\title{
DIE SPRACHLICHE REALISIERUNG DER TEXTSORTE "POLITISCHER APPELL" IM SLOWENISCHEN
}

1 Die Texte, die den Korpus für die folgende sprachliche Analyse bilden, möchte ich zuerst in bezug auf vier Kriterien darstellen: a) in bezug auf den Kanal, b) auf Zeit und Ort der Entstehung, c) auf den Textverfasser bzw. Schreiber und d) auf das Zielpublikunn.

a) Es handelt sich um Flugblattschriften, welche sich in der Geschichte als das zweckmässigste publizistische Mittel herausgestellt haben (und als solches gelten sie auch heute noch) wegen der einfachen Produktion, geringen Kosten und der effizienten Verbreitung. ${ }^{1}$ Es handelt sich um ein- ev. beidseitigbeschriftetes Blatt Papier vom Format A5, A6 oder A4, entweder gedruckt oder zyklostiert. Die Verbreitung verläuft schnell; es wird einfach unter die Leute ausgeteilt.

b) Die Texte sind in der Zeit zwischen dem 2. Weltkrieg auf slowenischem Gebiet entstanden (sie sind in slowenischer Sprache verfasst), d.h. in den Jahren 1941-45; der Kontrollkorpus auch schon vorher (1919-41). Die Zeit und der Ort sind hauptsächlich aus Konspirationsgründen nicht explizit angegeben. ${ }^{2}$ Wir können sie jedoch aus dem Inhalt des Textes erschliessen.

c) Es gibt mehrere "Sorten" Textverfasser/Schreiber; deshalb haben wir es auch mit mehreren Teilkorpussen zu tun. Diese tragen die Namen: NOB-Korpus ${ }^{3}$ (sog. Partisanen; 1941-45); $D M B$-Korpus ${ }^{4}$ (1941-45) - es handelt sich um die sog. antikommunistische Propaganda, produziert von den "Domobranci"/der Heimatwehr; NEM-Korpus ${ }^{5}$ (1941-45), d.h. ins Slowenische übersetzte Flugblätter, die von den Deutschen produziert wurden, welche das slowenische Territorium besetzt hatten; und KP-Korpus ${ }^{6}$ (1919-41) - die Kommunistische Partei hatte schon vor dem 2. Weltkrieg einen gut entwickelten Propagandaapparat. ${ }^{7}$

1 Vgl. K. Kirchner (1974: 9) und E. Dovifat (1968: 274).

2 Nur bei der Flugblattgruppe, die von den Deutschen produziert wurde (vgl. Punkt $1 \mathrm{c})-$ und ins Slowenische übersetzt wurde -, ist das Datum meistens angegeben. Die Texte galten nämlich als Passierschein.

3 Es handelt sich um 52 Texte.

$4 \quad$ Es handelt sich um 35 Texte.

$5 \quad$ Es handelt sich um 25 Texte. 
Die Propaganda war in kriegerischen bzw. "revolutionären" Verhältnissen verständlicherweise auf allen Seiten äusserst stark: alle waren sich nämlich bewusst, dass mit der Sprache beim Adressaten vieles zu erreichen ist. Ein Partisanenführer hat geschrieben: "In allen diesen Jahren des Befreiungskampfes hätte es unsere Erfolge ohne unsere Presse nicht gegeben.", 8 und ein anderer: "Unsere Presse wollte immer an der Spitze sein, nicht nur als Berichterstatter, sondern gleichzeitig als Führer, Propagator, Mobilisator und Organisator." ${ }^{9}$ Die Textverfasser traten auf den Flugblättern nicht als Einzelpersonen auf, sondern als Teil einer Institution, deren Name meistens nicht angeführt wurde. Alle Seiten hatten nämlich spezielle Organe für die Propaganda.

d) Die behandelten Texte auf den Flugblättern waren für die Öffentlichkeit bestimmt, für eine nicht näher definierten Menschenmasse, und zwar:

1) für jene, die sich noch für keine Seite entschieden hatten:

- im allgemeinen (so finden wir z.B. den Titel Slowenen und Sloweninnen! sowohl im NOB-Korpus als auch im DMB-Korpus) oder

- für einzelne Schichten oder Gesellschaftsgruppen (z.B. Dem Proletariat Sloweniens! im Korpus KP);

2) für jene, die schon Partei ergriffen hatten:

- vor allem für den Gegner, der auf "unsere" Seite übertreten sollte (z.B. An Euch, die Ihr den roten Stern auf der Mütze tragt - DMB-Korpus; Appell an alle von den Bolschewisten in die Wälder entführten Oberkrainer - NEMKorpus),

- in kleinerem Maße aber auch den eigenen Anhängern zur moralischen Aufmunterung (z.B. An die Anhänger der Heimatwehr - DMB-Korpus).

2.0 In der Folge möchte ich zuerst kurz den Begriff Textsorte und die theoretischen Ausgangspunkte für die sprachliche Analyse vorstellen.

2.1 Den politischen Appell als Textsorte kennzeichnet eine besondere Struktur, auf deren Grundlage der Adressat $u$. a. erkennt, zu welchem Zweck der Schreiber bzw. Sprecher den Text verfasst hat. In einigen Fällen wird der Zweck des Verfassers schon im Titel des Textes explizit genannt, z.B. eine Bestätigung, Gebrauchsanweisung, Bitte oder der vorher erwähnte Appell /an alle von den Bolschewisten in die Wälder entführten Oberkrainer/. Die Textsorte ist also Ausdruck der Intention des Textverfassers. Wenn wir uns auf die Seite des Adressaten stellen, können wir sagen, dass das Erkennen der Intention neben dem Thema ${ }^{10}$ entscheidend ist fürs Verständnis des Textes als Sin-

6 Es handelt sich um 26 Texte.

7 Vgl. Tomšič Tone, organizator partijskega tiska (1950).

8 Zit. nach R. Čenčič (1953: 1142).

9 Zit. nach M. Meršol (1984). 
neseinheit. Der Adressat erkennt den Sinn des Textes auf der Grundlage der Situationsbeurteilung. ${ }^{11}$

2.2 Die Pragmalinguistik mit der Sprechakttheorie ${ }^{12}$ hat das Interesse für die Intention des Textverfassers in den Mittelpunkt gestellt. Sie betrachtet den Verfasser als konkreten Specher/Schreiber, der in einer konkreten Situation mit einem konkreten Hörer/Leser kommuniziert, weil er auf ihn Einfluss nehmen will. Wenn der Verfasser mit dem Hörer/Leser kommuniziert, benutzt er die Sprache als Einfluss- bzw. Handlungsmittel. Und weil die pragmatische Analyse von der Erkenntnis ausgeht, dass Kommunikation Handlung ist, fasst sie die Sprache als Mittel zum Vollziehen von Sprechakten auf.

2.2.1 Nach J. R. Searle, ${ }^{13}$ einem der Begründer der Sprechakttheorie, setzt sich der Sprechakt abstrakt gesehen aus mehreren Teilakten zusammen: 1) Äußerungsakt, 2) propositionaler Akt, 3) illokutiver Akt, 4) perlokutiver Akt. Damit, dass der Sprecher den illokutiven Akt vollzieht, drückt er seine Intention aus (wozu), und mit der Realisierung des propositonalen Aktes, der sich zusammensetzt aus dem Referenz- und Prädikationsakt, den Inhalt (was). Wir kennen das Beispiel: Ich bitte dich, die Tür zuzumachen, in welchem die Intention im Hauptsatz ausgedrückt ist und der Inhalt im Nebensatz/Infinitivsatz.

Um seine Intention auszudruicken, hat der Sprecher/Schreiber direkte (Ich verlange, dass du die Tür zumachst. / Mach die Tür zu! / Die Tür zumachen! / Du musst die Tür zumachen.) oder indirekte Ausdrucksmöglichkeiten zur Wahl (Wir heizen. / Es zieht. / Friert es dich nicht? / Kommt noch jemand?)

Der Verfasser wählt beim Kommunizieren gewisse sprachliche Mittel (sowohl z.B. zum Ausdruck seiner Intention (wozu) als auch des Inhalts (was)) aus dem Speicher der Ausclrucksmöglichkeiten, welche er sich im Verlauf seines Lebens angeeignet hat (es handelt sich um grammatikalisch richtige Ausdrucksmöglichkeiten, die die ihm je entsprechende Sprache bietet). Die Auswahl verläuft gemäß der Situation, in der er sich befindet: er wählt unter den richtigen Ausdrucksmöglichkeiten (womit/wie) jene Möglichkeit, welche nach seinem Ermessen in der gegebenen Situation die zutreffende ist.

2.2.2 Wir kommunizieren hauptsächlich mittels einer Folge von Sprechakten. ${ }^{14}$ Ein Text kann als Realisierung einer Sprechaktkette ${ }^{15}$ dargestellt werden - auf der

10 Vgl. K. Brinker (1985: 51): "Das Textthema stellt /.../ die grösstmögliche Kurzfassung des Textinhaltes dar."

11 Unter Situation sind Ort, Zeit und sozio-ökonomische, sozio-kulturelle und psychische Bestimmungen gemeint.

12 Vgl. J. L. Austin (1962), J. R. Searle $(1971,1987)$ u. a.

13 J. R. Searle (1971: 40-42).

14 Vgl. W. Motsch/D. Viehweger (1981: 135), M. Brandt u. a. (1983: 106), D. Viehweger (1983: 382). 
Ebene der Intention mit der sog. Intentionsstruktur. ${ }^{16}$ Die Intentionsstruktur stellt die Strategie des Verfassers dar, um den Adressaten für sich zu gewinnen. Die genannte Intentionsstruktur nennen wir die Textsorte.

Wie jede andere Handlung ist auch die sprachliche Handlung strukturiert. Sie ist nicht nur die Summe der einzelnen Sprechakte, sondern ist hierarchisch organisiert. ${ }^{17}$ Die Intentionsstruktur des Textes drückt die Kette der Sprechakte (welche verschiedenen Typen zugehören kann) und die Relationen zwischen ihnen aus. Ein Sprechakttyp nimmt in dieser Struktur eine bedeutendere Stellung im Vergleich zu den anderen ein (d.h. ist dominant). Nach diesem dominanten Typ ist die ganze Intentionsstruktur, d.h. Textsorte, benannt (z.B. dominiert in einer Bitte der Sprechakt des Bittens, beim Danken jener des Dankens).

2.2.3 Der Erfolg eines Sprechaktes bzw. illokutiven Aktes (wir könnten auch sagen eines Intentionsaktes) ist abhängig von der Berücksichtigung der Situationsbedingungen durch den Sprecher/Hörer. Der Adressat muss die Angemessenheit jedes Sprechaktes in bezug auf die gegebene Situation beurteilen, z.B. würde der Adressat, wenn er älter/hierarhisch höher gestellt/ein Fremder ist, die Aufforderung "Mach die Tür zu!" bestimmt als unangebracht betrachten, und die Tür nicht schließen oder zumindest beleidigt sein. Zur Erleichterung der Beurteilung darüber, ob der dominante Sprechakt für den Adressaten angemessen ist, sieht der Sprecher - je nach Adressat - untergeordnete Sprechakte vor (das sind bei einer offiziellen schriftlichen Bitte z.B. Sprechakte des Behauptens, des Dankens und des Grüßens).

3 Kehren wir zu unserer Textsorte zurück, d.h. zum politischen Appell. Einen politischen Appell verfasst der Schreiber mit der Intention, den Adressaten dazu zu bringen, dass dieser etwas unternimmt bzw. nicht unternimmt, dass er eine Meinung übernimmt oder irgend etwas Konkretes ausführt - je nàch Wunsch des Schreibers. Das eine wie das andere sollte zu einem günstigeren Zielzustand führen, der auf den bestehenden ungünstigen Zustand folgt. Wenn der Leser das Verlangte nicht ausführt, würde dies zu einem noch ungünstigeren Zustand führen. ${ }^{18}$ Der Leser hat die Möglichkeit, selbst zu entscheiden, ob er jenes, wozu man ihn auffordert, tun soll oder nicht. Der Verfasser ist sich dessen bewusst, deshalb stellt er dem Leser die Angelegenheit als gemeinsames bzw. breiteres Gesellschaftsproblem dar. Das Verhältnis zwischen den Kommunikationsteilnehmern ist nämlich nicht hierarchisch - dass also der Leser gehorchen müsste -, es

Vgl. S. J. Schmidt (1973: 140), D. Wunderlich (1974: 347).

16 Der Text hat auch eine thematische Struktur, die ebenso wie die Intentionsstruktur sprachlich realisiert wird - das soll uns hier aber nicht interessieren.

17 Vgl. W. Koch/I. Rosengren/M. Schonebohm (1981: 161), M. Brandt u. a. (1983: 112), D. Viehweger (1983: 378), W. Motsch/R. Pasch (1987: 72-73), W. Motsch/M. Reis/I. Rosengren (1990: 120). 
ist aber auch nicht gleichwertig, jedenfalls nicht vom Standpunkt der Kenntnisse aus. (Der Schreiber tut so, als ob er über die Angelegenheit viel besser informiert wäre.) ${ }^{19}$

Die Intentionsstruktur des politischen Appells beinhaltet neben dem dominanten Sprechakt des Appells auch die untergeordneten Sprechakte des Behauptens, und zwar in umgekehrter Reihenfolge: zuerst die Sprechakte der Behauptung, dann die Sprechakte des Appells.

3.1 Am Ende stellen wir die Resultate der Textanalyse vor.

3.1.1 Befassen wir uns zuerst mit der sprachlichen Realisierung des dominanten Sprechaktes des Appells. Wie haben die Schreiber eines politischen Appells den Sprechakt des Appells sprachlich realisiert? Und unterscheiden sich die Sprachmittel, die sie ausgewählt haben in bezug auf die Teilkorpusse?

Die Ausdrucksmöglichkeiten sind in der folgenden Reihenfolge aufgeführt: von der direkten Form bis zur indirekten. (Die Beispiele mit den erwähnten Sprachmitteln sind aus allen Korpussen gewählt - und ins Deutsche übersetzt. In Klammer ist der Korpustitel und das Entstehungsjahr aufgeführt. Daneben befindet sich noch ein Schema, das zeigt, mit welcher Häufigkeit dieses Sprachmittel in den jeweiligen Teilkorpussen auftritt.)

- Das performative Verb: auffordern (1), im übertragenen Sinn rufen (2):

(1) Pozivam vse Gorenjce, ki so prišli po ZMOTI, ZAPELJAVI ALI SILI k boljševiškim tolpam, da gozdove zapuste, se vrnejo $v$ domači kraj in se tam prijavijo nemškim varnostnim organom. (NEM 1 1943)

Ich fordere alle Oberkrainer, die durch IRRTUM, VERFUEHRUNG ODER ZWANG zu den bolschewistischen Banden gekommen sind, auf, die Wälder zu verlassen, in die Heimatorte zurückzukehren und sich dort den deutschen Sicherheitsbehörden zu stellen.

KP NOB DMB NLM

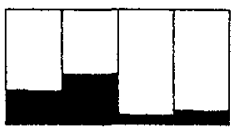

(2) Osvobodilna fronta kliče vse Slovence v poslednji boj proti okupatorju za osvoboditev domovine! /.../ Osvobodilna fronta kliče $v$ poslednji boj vse Slovence, ki so doslej še čakali ob strani. Osvobodilna fronta kliče vse, ki so bili zapeljani in zaslepljeni /.../ Osvobodilna fronta kliče vse delavce, kmete, obrtnike, nameščence, intelektualce, ki še vedno s svojim delom doma in v tujini služijo okupatorju. /.../ (NOB 1 - 1944)

Die Befreiungsfront (OF) ruft alle Slowenen in den Endkampf gegen die Besatzer zur Befreiung der Heimat! /.../ Die Befreiungsfront ruft alle Slowenen in den Endkampf, die bis jetzt unentschlossen gewartet haben. Die Befreiungsfront ruft alle Verführten und Verblendeten. /... Die Befreiungsfront ruft alle Arbeiter, Bauern, Handwerker, Angestellten, Intellektuellen, welche mit ihrer Arbeit zu Hause und in der Fremde der Besatzung dienen. /...

19 Die angeführten Situationsbedingungen sind wichtig für die Auswahl von Ausdrucksmöglichkeiten, die im Kapitel 3.1.1 gezeigt sind. 
- Befehlsform für die 2. Person Plural (3) oder 2. Person Singular (4) oder 1. Person Plural (5):

(3) /Belogardisti!/ Predajte se! Bežite iz belogardističnih vrst! Ne služite več Italijanom in izdajalski slovenski gospodi! (NOB 2 - 1942)

/Weißgardisten/, ergebt Euch! Flieht aus den Reihen der Weißgardisten! Dient nicht länger den Italienern und den verräterischen slowenischen Herren!
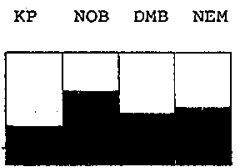

(4) Ne daj se zaslepiti od komunistične banditske organizacije! (NEM 2 - 194?)

Lasse Dich von der kommunistischen Banditenagitation nicht verblenden!

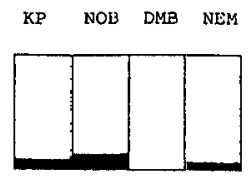

(5) Domobranci, izza temnih oblakov že sije sonce svobode, zato podvojïmo svojo borbenost in zmaga bo naša! (DMB 1 - 1944)

Angehörige der Heimatwehr, hinter den dunklen Wolken strahlt schon die Sonne der Freiheit. Lasst uns darum unseren Kampfeswillen verdoppeln. und der Sieg wird unser sein!

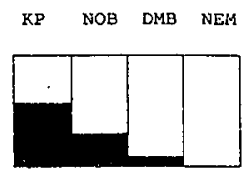

- Aufforderungssatz unter Auslassung des Verbs (ellyptisch) (6):

(6) Niti zrna žita napadalcem proti SSSR in okupatorjem slovenske zemlje! (NOB 3 - 1941)

Kein einziges Getreidekorn für den Angreifer der UdSSR und den Besatzer der slowenischen Erde!

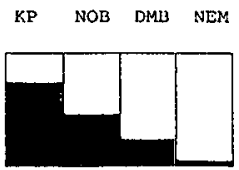

- Aussagesatz mit modalem Ausdruck, der eine Verpflichtung zum Ausdruck bringt: müssen (7), es ist nötig, ist unsere Pflicht, es ist an der Zeit, wir sind es schuldig 
(7) To kugo (skrunjenje žensk, op. M. B.) iztrebiti, mora biti vsakega Gorenjca sveta volja, kateri hoče dom, narod in rodbino ohraniti! (NEM 3 -1944)

Diese Pest (Frauenschande, Anm. M. B.) auszurotten, muss der heilige Wille aller Oberkrainer sein, die Heimat, Volk und Familie erhalten wollen!

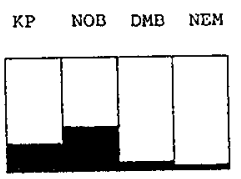

- Aussagesatz mit Verb im Futur (8):

(8) Delavci in kmetje bodo pretvorili imperialistično vojno v meščansko vojno proti lastni buržoaziji! (KP 1 - 1936)

Die Arbeiter und Bauern werden den imperialistischen Krieg in einen Bürgerkrieg gegen die eigene Bourgeoisie umwandeln!

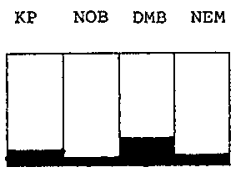

- Aussagesatz, der alternative Möglichkeiten beinhaltet (entweder - oder) (9):

(9) Naša pot je ravna in jasna in čista. Mi razlikujemo samo dve odločitvi in dve izbiri za vsakega Slovenca:

ali z okupatorji in domačimi narodnimi izdajalci, torej s sovražniki slovenskega naroda in bratomorilci, $v$ gotovo pogubo - ali z Narodno - osvobodilno vojsko, podprto z zmagovitimi silami velikih zavezniških armad, predvsem bratske Rdeče armade in z Osvobodilno fronto slovenskega naroda $k$ bližnji zmagi, lepši bodočnosti in sreči! (NOB 4 - 1944)

Unser Weg ist eben, klar und rein. Für uns stehen einem jeden Slowenen zwei Möglichkeiten zur Wahl: entweder mit dem Besatzer und den einheimischen Volksverrätern, d.h. den Feinden des slowenischen Volkes und den Brudermördern, ins sichere Verderben - oder aber mit der Volksbefreiungsarmee, unterstützt von den siegreichen Kräften der großen Verbündetenarmeen, vor allem der brüderlichen Roten Armee und mit der Befreiungsfront des slowenischen Volkes in den nahen Sieg, eine schönere Zukunft und ins Glück!

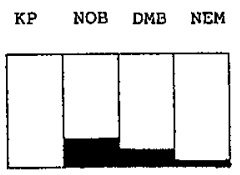

- Aussagesatz mit einer allgemeinen Behauptung (mit der Bedeutung 'Mach das nicht!') (10):

(10) Kdor boljševikom pomaga, prinaša nesrečo svojemu narodu! (NEM 4 - 1944)

Wer den Bolschewisten hilft, bringt Unglück über sein Volk! 
- Fragesatz (in welchem der Schreiber den Adressaten fragt, was er in der vorliegenden schlechten Situation tun wird, ob er noch weiterhin Negatives tun wird) (11):

(11) Ali hočěs še v bodoče držati streme onim, ki si izsiljujejo tvoje "zaupanje" samo z javnim glasovanjem, nasiljem in podkupovanjem? Ali hočeš, da naj tudi $v$ bodoče vladajo ti samozvani "voditelji" brez tebe, mimo tebe in proti tebi? Ali hočeš, da bodo ti ljudje še nadalje izkoriščali tvojo razcepljenost in neenotnost zato, da bi preprečili tvojo borbo za mir, svobodo in kruh? (KP 2 - 1939) Möchtest Du auch in Zukunft jenen den Steigbügel halten, die sich Dein "Vertrauen" nur durch öffentliche Abstimmungen, Gewaltanwendung und Bestechung erzwingen? Willst $\mathrm{Du}$, dass diese selbsternannten "Führer" auch weiterhin regieren - ohne Dich, an Dir vorbei und gegen Dich? Willst $\mathrm{Du}$, dass diese Leute noch weiter Deine Unentschlossenheit und Gespaltenheit dazu ausnutzen, um Deinen Kampf für Frieden, Brot und Freiheit zu verhindern?

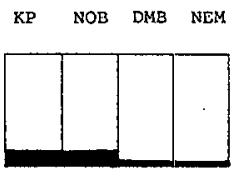

3.1.2 Untergeordnete Sprechakte der Behauptung, die der Schreiber vor dem Sprechakt des Appells ausführt, haben eine besondere Funktion: den Adressaten dazu zu motivieren, dass er genau das tut, wozu ihn der Schreiber am Ende des Textes auffordert. Sie begründen den Appell. Bei der Textanalyse hat sich herausgestellt, dass der Schreiber mit den Behauptungen am Textanfang (wie viele es davon gibt, beurteilt wiederum der Schreiber unter Berücksichtigung der Vorkenntnisse des Adressaten) die negativen Verhältnisse erläutert und bewertet. Wenn solche Verhältnisse noch in Zukunft anhalten sollten, wäre dies für beide noch schlimmer.

Die Sprechakte der Behauptung werden sprachlich wie folgt realisiert; die Ausdrucksmöglichkeiten sind von der direkten Form bis zur indirekten aufgeführt.

- Aussagesatz (12):

(12) Sami ste priče dogodkov, ki jih vsi preživljamo že nad dve leti pod partizansko strahovlado. Strašne so žrtve, ki jih prestajamo! Koliko nedolžnih ljudi je moralo dati svoje nedolžno življenje, koliko škode smo že utrpeli! (DMB 2 - 1943-44)

Ihr seid selbst Zeugen der Ereignisse, welche wir schon seit über zwei Jahren unter der Schreckensherrschaft der Partisanen erlebt haben. Was für entsetzliche Opfer wir haben bringen müssen! Wieviele unschuldige Menschen mussten ihr Leben lassen! Der uns zugefügte Schaden ist unermeßlich! 
- Fragesatz (Ergänzungsfrage), auf welche Aussagesätze folgen (das ist keine Frage, auf die der Adressat die Antwort geben müsste, sondern zusammen mit der Antwort eine Behauptung, welche die Aufmerksamkeit des Adressaten weckt; gleichzeitig erleichtert der Fragesatz das Verständnis, weil er damit klare Inhaltspakete des Textes definiert) (13):

(13) /.../ je tako imenovana "osvobodilna fronta". /.../ Kdo vodi to organizacijo? Peščica komunističnih voditeljev. (DMB 3 - 1941)

/.../ ist die sogenannte "Befreiungsfront". /.../ Wer leitet diese Organisation? Eine Handvoll kommunistischer Anführer.

KE NOB DMB NEM

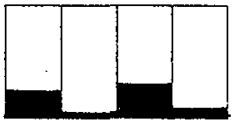

3.1.2.1 Die folgenden Sprechakte der Behauptung dienen der zusätzlichen Motivation des Adressaten, jenes zu tun, wozu ihn der Schreiber mit dem Sprechakt des Appells auffordert. Weil sie nicht mehr "obligatorisch" in der gegebenen Struktur sind, habe ich sie von ersteren getrennt.

Diese Sprechakte der Behauptung werden wie folgt realisiert:

- direkt mit Aussagesätzen, in welchen sich der Schreiber zur Wehr setzt gegen die Beurteilung der Lage durch seine Gegner und gegen die Darstellung der eigenen Handlungsweise durch den Gegner (14), über seine Erfolge bzw. von den Erfolgen seiner Verbündeten (15) oder von seinen Zielen schreibt (16), oder aber das Unsittliche/die Amoral des Gegners sowie die schlechten Verhältnisse beim Gegner aufzeigt (17):

(14) Tako OF že tri leta laže: Polom Nemčije - razpad nemških armad na frontah - predstoječi konec okupatorja $v 14$ dneh, konec meseca, spomladi, poleti, prav sigurno pozimi ... in ponovno prav sigurno spomladi .../.../

OF je na vseh mogočih letakih predstavila Gorenjcem sledeče: "Naša moč je na Gorenjskem vedno večja, naši udarci razbijajo edinice okupatorjev! Položaj na frontah je tak, da se dnevno računa na razpad Hitlerjeve Nemčije."

Slovenski poročevalec piše v juniju 1942: "V tem letu bomo mi fašistično Nemčijo uničili." /.../

Tako hočejo Vas Gorenjce na račun bolševiške svetovne revolucije izvabiti v smrt. /.../ Del teh pa je hudičev namen Stalina spoznal, kateri zahteva Vaše glave, da bi bolševiško svetovno državo zgradil. Vsi ti so ušli od tolp in prišli nazaj. (NEM 5 - 1944)

So belïgt Euch die OF seit 3 Jahren: Zusammenbruch Deutschlands - Zerfall der deutschen Armeen an den Fronten - bevorstehendes Ende der Okkupatoren in 14 Tagen, zum Monatsende, im Frühjahr, im Sommer, ganz sicher aber im Winter ... und erneut ganz sicher im Frühjahr .../...

Die bolschewistische OF hat in allen möglichen Flugblättern den Oberkrainern folgendes vorgesetzt: Unsere Macht wird in Oberkrain immer grösser, unsere Schläge zertrümmern die Einheiten der Okkupatoren! Die Lage an den Fronten ist derart, dass man täglich mit dem Zerfall von HitlerDeutschland rechnen kann." 
Slowenischer OF-Berichterstatter im Juni 1942: "In diesem Jahr werden wir das faschistische Deutschland vernichten!" /...I

So wollen sie Euch Oberkrainer auf Rechnung der bolschewistischen Weltrevolution in den Tod locken. /.../ Ein Teil hat die teuflische Absicht des Henkers Stalin erkannt, der Eure Köpfe verlangt, um einen bolschewistischen Weltstaat aufzubauen. Dieser ist von den Banden entlaufen und zurückgekehrt.

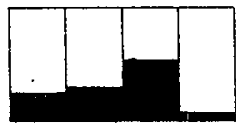

(15) 23. avgusta je minilo leto dni, odkar je bil sklenjen nenapadalni pakt med Sovjetsko zvezo in Nemčijo. /.../V teku tega leta se je pokazalo, kako ogromne koristi je bil ta pakt ne le za Sovjetsko zvezo, marveč tudi za mnoge druge narode, ki so se spričo njega izognili dosedanjim vojnim strahotam. Sovjetska zveza je spričo tega pakta lahko v miru nadaljevala z izgraditvijo socializma in z dviganjem blagostanja dvestomilijonske bratske skupnosti, ki se imenuje Sovjetska Zveza. (KP 3 - 1940)

Am 23. August ist ein Jahr vergangen, seit die Sowjetunion mit Deutschland einen Nichtangriffspakt abgeschlossen hat /.../Im Laufe dieses Jahres hat sich gezeigt, von wie großem Nutzen dieser Pakt für die Sowjetunion ist; aber auch viele andere Völker konnten dank ihm den bisherigen Schrecken des Krieges entrinnen. Die Sowjetunion hat dank diesem Pakt mit dem Aufbau des Sozialismus und dem Erhöhen des Wohlstandes der zweihundert Millionen starken Bruderschaft, die Sowjetunion heißt, in Frieden fortfahren können.

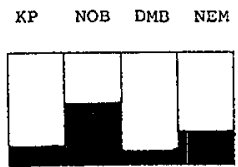

(16) Narodna osvoboditev je glavni cilj Osvobodilne fronte, ki je danes edina predstavnica slovenskega naroda. Naš prvi cilj je osvoboditev, a po končani osvoboditvi bo naš slovenski narod na temelju ljudske demokracije sam sklepal o svoji samoodločbi, o svoji družbeni obliki. (NOB 5 - 1942)

Die Befreiungsfront, die heute einzige Vertreterin des slowenischen Volkes, hat zum Hauptziel die Befreiung des Volkes. Das erste Ziel ist die Befreiung, nach deren Erlangung aber wird unser slowenisches Volk auf der Grundlage einer Volksdemokratie selber über seine Selbstbestimmung und seine Gesellschaftsform entscheiden.

(17) $T u$

dobra hrana

dobro ravnanje

spodobna obleka

snažno prenočišče

zdavniška nega

zadostna plača

preskrba in podpora potrebnih

(DMB 4 - 1944)
KP NOB DMB NEM

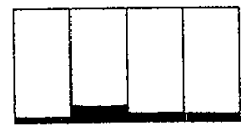

Tam

nezadostna prehrana, glad

teror, udarci, nasilje

cunje in cape

živalsko življenje po brlogih

kuge in bolezni

nevarnosti in nehvaležnost

umor in požig 
Hier

gute Nahrung

gute Behandlung

angemessene Bekleidung

saubere Unterkunft

ärztliche Fürsorge

genügende Entlöhnung

Versorgung und Unterstützung

der Bedürftigen
Dort

ungenüngende Ernährung, Hungersnot

Terror, Schläge, Gewalt

Lumpen und Fetzen

tierähnliches Leben in Höhlen

Krankheiten

Gefahren und Undankbarkeit

Mord und Todschlag

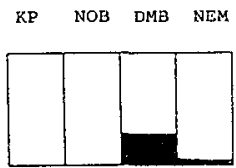

- indirekt mit Fragesätzen (Entscheidungsfragen) (18):

(18) Vojni vihar se vse bolj divje razvija ter se že približuje mejam nemškega rajha. Nemška fronta na vzhodu doživlja vedno silnejše udarce junaške ruske Rdeče armade, italijanska in nemška mesta se spreminjajo v prah, zapadu in jugu Evrope se neizbežno bliža nova fronta. Kdo med vami more še verjeti v nemško zmago? Kdo med vami še ne zaupa premoči zaveznikov in načela o samoodločbi narodov? (NOB 6 - 1942)

Der Kriegssturm wütet immer heftiger und nähert sich schon den Grenzen des Deutschen Reiches. Der deutschen Ostfront werden immer heftigere Hiebe versetzt durch die heldenmütige russische Rote Armee, die italienischen und deutschen Städte zerfallen zu Staub, West- und Südeuropa nähert sich unausweichlich einer neuen Front. Wer unter euch kann noch an den deutschen Sieg glauben? Wer unter euch glaubt noch nicht an die Uebermacht der Alliierten und an das Prinzip der Selbstbestimmung der Völker?

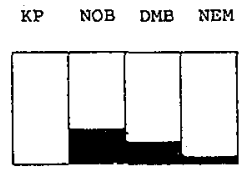

3.1.3 Zusammenfassend können wir sagen, dass für den politischen Appell eine dreiteilige Struktur typisch ist (I. Teil: die Sprechakte der Behauptung, II. Teil: die Sprechakte der Behauptung (nicht obligatorisch), III. Teil: Sprechakte des Appells). Die vier Teilkorpusse weisen im Vergleich verschiedene Länge auf: bei dem KP-Korpus ist der umfangsreichste der III. Teil, bei den DMB-Korpus und NEM-Korpus der II. Teil, beim NOB-Korpus sind alle 3 Teile ungefähr gleichlang.

Die angeführte Struktur und die vorgestellten Ausdrucksmittel dünkten dem Schreiber die wirksamsten zu sein, deshalb hatte er sie verwendet. Gleichzeitig hat er mit ihnen die Bedingungen erfüllt, von denen wir schon vorher gesagt haben, dass sie konventionell mit dem Sprechakt des Appells verbunden sind. Die Bedingungen entstehen aus dem Verhältnis zwischen den Kommunikationsteilnehmern: das Verhältnis 
zwischen ihnen ist aus der Gesamtstruktur ersichtlich, vor allem aus der Intentionserklärung, d.h. im dominanten Sprechakt des Appells.

Dass sich der Schreiber die Handlung intensiv wünscht und sie als im Interesse der Allgemeinheit darstellt, zeigt folgendes: er verwendet neben der Befehlsform der 1. Person Plural noch die Anführung seines Zieles und der Werte und Normen der Gesellschaft, in der sowohl der Schreiber als auch der Adressat leben; es ist typisch, dass es dem Adressaten überlassen ist, ob er sich für die Handlung entscheiden will oder nicht, was mit der disjunktiven Hypotaxe realisiert ist.

4 Weil sich die angeführten Ausdrucksmöglichkeiten in allen analysierten Texten finden (die Ausnahmen sind aus den Schemas ersichtlich), ist damit die These bestätigt, dass der politische Appell als Textsorte mit einer ganz bestimmten Struktur für alle vier behandelten Teilkorpusse gültig ist (ungeachtet dessen, dass die Autoren verschiedenen politischen/ideologischen Lagern angehören). Dabei ist die sprachliche Realisierung der Textsorte möglicherweise sehr verschieden, im großen und ganzen aber sehr ähnlich.

\section{Ouellenverzeichnis}

NOB 1 Domobranci! (Archiv INZ, II/F. VI)

NOB 2 Vsem belogardistom v premislek in odločitev (AINZ, I-87)

NOB 3 Slovenskemu narodu! (AINZ, F. I-46)

NOB 4 Sovražniki slov. naroda pod različnimi barvami in imeni (AINZ, II/F. VII)

NOB 5 Slovenci! (AINZ, F. I-114)

NOB 6 Koroškim Slovencem! (AINZ, I/73)

DMB 1 Slovenskim domobrancem (AINZ, F. 24a)

DMB 2 Slovenci! Rojaki! (AINZ, F. 24a)

DMB 3 Slovenke, Slovenci! (AINZ, F. 24a)

DMB 4 Zapeljanci! (AINZ, F. 24a)

NEM 1 Poziv na vse od boljševikov v gozdove odpeljane Gorenjce / Appell an alle durch die Bolschewisten in die Wälder verschleppten Oberkrainer (AINZ, F. 17/I)

NEM 2 Preseljevalo se ne bo več! / Es wird nicht umgesiedelt! (AINZ, F. 17/I)

NEM 3 Skrunilci žensk na delu! / Frauenschänder am Werk! (Ainz, F. 17/I)

NEM 4 Mera je polna / Das Mass war voll (AINZ, F. 24/III)

NEM 5 Tako OF Vam Gorenjcem že tri leta laže / So belügt Euch die OF seit 3 Jahren (AINZ, F. 17/I)

KP 1 - (Archiv ACK, Letaki I/1)

KP 2 Vsemu delovnemu ljudstvu Slovenije (ACK, Letaki I/3)

KP 3 Delavci, kmetje, meščani! Vojaki in oficirji Jugoslavije! (Bibliothek NUK 312/11) 


\section{Literaturverzeichnis}

Austin, J. L. (1962), How to Do Things with Words, Oxford.

Brandt, M. u. a. (1983), Der Einfluss der kommunikativen Strategie auf die Textstruktur - dargestellt am Beispiel des Geschäftsbriefes. In: I. Rosengren (Hrsg.), Sprache und Pragmatik, Lunder Symposium 1982, Malmö, S. 105-136.

Brinker, K. (1985), Linguistische Textanalyse, Berlin.

Čenčič, R. (1953), Pravično priznanje tisku, Tovariš, 1142.

Dovifat, E. (1968), Handbuch der Publizistik, Band 1, Berlin.

Kirchner, K. (1974), Flugblätter, München.

Koch, W./Rosengren, I./Schonebohm, M. (1981), Ein pragmatisch orientiertes Textanalyseprogramm. In: Lunder Germanische Forschungen 50, S. 155-203.

Meršl, M. (1984), Naš časopis in čas, 26. 4.-3. 7.

Motsch, W.Pasch, R. (1987), Illokutive Handlungen. In: W. Motsch (Hrsg.), Satz, Text, sprachliche Handlung, Studia grammatica XXV, Berlin, S. 11-80.

Motsch, W./Reis, M./Rosengren, I. (1990), Zum Verhältnis von Satz und Text, Deutsche Sprache, Berlin, 97-125.

Motsch, W./Viehweger, D. (1981), Sprachhandlung, Satz und Text. In: I. Rosengren (Hrsg.), Sprache und Pragmatik, Lunder Symposium 1980, Malmö, S. 125-153.

Schmidt, S. J. (1973), Texttheorie, München.

Searle, J. R. (1971), Sprechakte, Frankfurt/Main.

--- (1979), Expression and Meaning, Cambridge.

Tomšič Tone, organizator partijskega tiska (1950), Ljudska pravica 9. 5. 1950.

Viehweger, D. (1983), Sequenzierung von Sprachhandlungen und Prinzipien der Einheitenbildung im Text. In: R. Ružička/W. Motsch (Hrsg.), Untersuchungen zur Semantik, Studia grammatica XXII, Berlin, 369-394.

Wunderlich, D. (1974), Grundlagen der Linguistik, Reinbek.

\section{Povzetek}

JEZIKOVNA URESNIČITEV BESEDILNE VRSTE "POLITIČNI POZIV" V SLOVENSKEM JEZIKU

V članku so predstavljeni rezultati jezikovne analize besedil iz obdobja od 1919 do 1945, napisanih v slovenskem jeziku, ki pripadajo tipu besedila "politični poziv". Na podlagi pragmatičnih teoretičnih izhodišč je predstavljena njihova $t$. i. namenska / ilokucijska zgradba, ki kaže sporočevalčevo strategijo pridobivanja naslovnika, da bi ta storil to, $\mathrm{k}$ čemur ga sporočevalec poziva. Omenjena zgradba in jezikovna sredstva, ki jih je sporočevalec kot najbolj učinkovita uporabil za izrazitev svojega namena, se (v obravnavanem obdobju) ne ločujejo glede na to, da njihovi avtorji pripadajo različnim političnim / ideološkim "taborom" tj. 1941-45: NOB (partizani), DMB (domobranci), NEM (Nemci), 1919-41: KP (Komunistična partija)). 